\title{
Maturação e qualidade de frutos de mandacaru (Cereus jamacaru P.DC.) de diferentes bioclimas do estado da Paraíba ${ }^{1}$
}

\author{
Raylson de Sá Melo ${ }^{2}$, Silvanda de Melo Silva ${ }^{3}$, Alex Sandro Bezerra de Sousa ${ }^{2}$, Renato Pereira Lima ${ }^{4}$, Ana Lima \\ Dantas $^{5}$, Renato Lima Dantas ${ }^{5}$, Vanda Maria de Aquino Figueiredo ${ }^{6}$
}

\begin{abstract}
${ }^{1}$ Submetido em 19-04-2017 e aprovado em 16-10-2017
${ }^{2}$ Mestrando do Programa de Pós-graduação em Agronomia, Universidade Federal da Paraíba (UFPB), Areia- PB. CEP: 58397-000. e-mail: raylsonmello@gmail.com; lexsandro.2012@gmail.com

${ }^{3}$ Professora Titular, Centro de Ciências Agrárias, Universidade Federal da Paraíba (UFPB), Areia- PB. CEP: 58397000. e-mail: silvasil@cca.ufpb.br

${ }^{4}$ Doutorando do Programa de Pós-graduação em Agronomia, Universidade Federal da Paraíba (UFPB), Areia- PB. CEP: 58397-000. e-mail: renatolima.p@gmail.com

${ }^{5}$ Pesquisador PDJ/CNPq do Programa de Pós-graduação em Agronomia, Universidade Federal da Paraíba (UFPB), Areia- PB. CEP: 58397-000. e-mail: dantas.ana.lima@gmail.com; renato_dantas@ hotmail.com.br

${ }^{6}$ Estudante de Agronomia, Centro de Ciências Agrárias, Universidade Federal da Paraíba (UFPB), Areia- PB. CEP: 58397-000. e-mail: vandam.aquino@hotmail.com
\end{abstract}

\begin{abstract}
RESUMO - Frutos não tradicionais como os de Cereus jamacaru DC são fontes de fitonutrientes importantes para a saúde, além de constituir uma alternativa alimentícia em épocas secas até para os animais. Este trabalho teve por objetivo avaliar a qualidade nutricional e funcional de frutos de mandacaru em diferentes estádios de maturação (Verde Claro (VC), Inicio de Pigmentação (IP), Inicio de Pigmentação Vermelho (IPV), Pigmentado Vermelho (PV), Totalmente Vermelho (TV)), visando agregação de valor através da diversificação de seus usos na região e explorando o potencial dos frutos como alimento funcional. Os frutos de mandacaru foram colhidos no município de Campina Grande-PB e Barra de Santa Rosa-PB. O delineamento experimental utilizado foi inteiramente casualizado e doze frutos (quatro repetições de três frutos) foram colhidas de cada estádio de maturação. Os dados obtidos das variáveis físicas, físicoquímicas, polifenóis extraíveis totais e atividade antioxidante foram submetidos à análise de variância pelo teste $\mathrm{F}$ e as médias foram comparadas pelo teste de Tukey em até 5\% de probabilidade. Os frutos de mandacaru apresentam elevado rendimento de polpa no estádio de maturação maduro (TV-totalmente vermelho) e coloração de casca que evoluiu de verde pigmentado para a coloração avermelhada com o avanço da maturação. Os sólidos solúveis, a relação SS/AT e pH dos frutos aumentou com o avanço da maturação, enquanto a acidez titulável diminuiu, todos estes tendendo a se estabilizar no estádio IPV, indicando ser este o ponto de colheita. Isso torna esses frutos adequados para o consumo fresco e para serem processados. Os frutos de mandacaru apresentam um alto conteúdo de polifenóis extraíveis totais em todos os estádios de maturação e uma elevada atividade antioxidante total, justificando assim o seu consumo, além de servir como estímulo ao seu melhor aproveitamento.
\end{abstract}

Palavras-chave: Cactaceae; Qualidade; Potencial funcional; Maturação.

\section{Maturation and quality of mandacaru (Cereus jamacaru P.DC.) fruit from different bioclimates of Paraíba State - Brazil}

\begin{abstract}
Non-traditional fruits such as those of Cereus jamacaru DC are source of phytonutrients important for health, besides being a food alternative in dry seasons even for the animals. The objective of this work was to evaluate the nutritional and functional quality of mandacaru fruits in different stages of maturation (Light green (VC), Beginning of Pigmentation (IP), Beginning of Red Pigmentation (IPV), Red Pigmented (PV), Completely Red (TV)), aiming to aggregate value through the diversification of their uses in the region and exploring the potential of these fruits as functional food. The mandacaru fruits were harvested in the municipalities of Campina Grande and Barra de Santa Rosa, Paraíba State-Brasil. The experimental design was the completely randomized and twelve fruits (four replications of three fruits) were harvested of each maturity stage. The data obtained from the physical, physicochemical variables, total extractable polyphenols and antioxidant activity were submitted to analysis of variance by the $\mathrm{F}$ test and the means were compared by the Tukey test at up to 5\% probability. The mandacaru fruits presented a high yield of pulp at full maturity stage (TV - totally red) and the color of skim evolved from light green to full reddish color with the advance of maturation. The soluble solids, SS /AT ratio and $\mathrm{pH}$ of fruits increased with maturation advancement, while titratable acidity decreased, all of these tending to stabilize at the IPV stage, indicating that this is the harvest point. This makes these fruits suitable for fresh consumption and to be processed. Cereus jamacaru fruits have a high content of total extractable polyphenols at all maturation stages and a high total antioxidant activity, thus justifying their consumption, besides serving as a stimulus to their better use.
\end{abstract}

Keywords: Cactaceae; Quality; Functional potential; Maturation. 


\section{Introdução}

O consumo de frutas e hortaliças tem sido cada vez mais promovido devido ao benefício trazido pela ingestão de compostos químicos vegetais que podem reduzir o estresse oxidativo causado pelo acúmulo de radicais livres (WANG et al., 2011; NEPAL et al., 2012). É necessário, então, identificar fontes vegetais que possuam fitonutrientes com alegação funcional e de promoção de saúde e caracterizá-los (GARCÍACRUZ et al., 2016). Nesse contexto, frutos não tradicionais no mercado, a exemplo dos de cactáceas, podem servir como fonte desses compostos, além de enriquecerem a alimentação nas regiões de ocorrência desses frutos (DAVET et al., 2009; LUCENA et al., 2015).

Dentre as cactáceas nativas do Nordeste, o mandacaru (Cereus jamacaru DC) se destaca como alternativa alimentar e fonte de água para os animais nas épocas secas, sendo um dos principais suportes forrageiros de ruminantes (PAULINO et al., 2011). O mandacaru, é um cacto colunar, característico da região semiárida do Brasil (ROCHA; AGRA, 2002), apresentando uma série de usos nessa região, como para a construção (LORENZI; MATOS, 2002), forragem para os animais (LUCENA et al., 2015), sendo também de grande importância medicinal, havendo relatos de usos de diversas partes da planta, como as raízes (ANDRADE, MARQUES e ZAPPI, 2006), o caule (MESSIAS et al., 2010), as flores (GONZÁLES-HERNÁNDEZ; VILLARREAL 2007), como também o fruto (SILVA; ALVES, 2009; NUNES et al., 2013).

Além da utilização como fármaco, estudos etnobotânicos constataram o consumo do fruto do mandacaru fresco como alimento humano (LUCENA et al., 2015; ANDRADE; MARQUES; ZAPPI, 2006). Os frutos são basiformes, e em geral, grandes e vermelhos, de polpa adocicada, e muito apreciados por animais e pelo homem (ANDERSON, 2001; SALES et al., 2015) . Muitas famílias das áreas de ocorrência de plantas preparam compotas de doce da polpa desta cactácea e as comercializam em rodovias e feiras (PAULINO et al., 2011). Neste sentido, Nunes et al. (2013) destacaram que os frutos do mandacaru apresentam grande potencial para a indústria, por apresentarem teores elevados de sólidos solúveis e açúcares totais, constituintes importantes em processos tecnológicos.
Portanto, para o máximo aproveitamento das características de qualidade dos frutos do mandacaru é necessário a determinação do estádio de maturação ideal para a colheita, bem como as diferenças na qualidade quanto aos bioclimas de ocorrência dos frutos. Uma dificuldade para definir o ponto de colheita com a máxima qualidade é que esta é notoriamente variável nos frutos (GALINDO et al., 2015). Além disso, a qualidade de frutos pode diferir na mesma espécie e nos diferentes locais de ocorrência (SHEWFELT, 1999).

Nesse sentido, estudos mais amplos sobre maturação para a colheita de frutos do mandacaru se fazem necessários, visto que há poucos registros de informações sobre a evolução da maturação e o ponto de colheita destes frutos. Portanto, sendo este um fruto de grande importância socioeconômica para a região Nordeste, este trabalho teve por objetivo avaliar as mudanças na qualidade, compostos bioativos e atividade antioxidante de frutos de mandacaru nos seus diferentes estádios de maturação, visando definir um índice de maturidade viável que auxilie a definir o ponto de colheita, buscando valorizar a qualidade e viabilizar outras formas de aproveitamento, bem como explorar o potencial destes frutos como alimento funcional.

\section{Material e Métodos}

Os frutos do mandacaru (Cereus jamacaru) foram colhidos de plantas adultas em áreas rurais dos município de Campina GrandePB (Bioclima da Mesoregião Agreste) e Barra de Santa Rosa-PB (Bioclima da Microrregião Curimataú), tomando-se como base a evolução da maturação por meio da coloração da casca (Figura 1). Desta forma, com base na disponibilidade de frutos, foram estabelecidos cinco estádios de maturação para os frutos colhidos em Campina Grande-PB e três estádios para os frutos colhidos em Barra de Santa Rosa-PB (Tabela 1). Após a colheita, os frutos foram levados ao Laboratório de Biologia e Tecnologia Pós-colheita do Centro de Ciências Agrárias, da Universidade Federal da Paraíba (LBTPC/CCA/UFPB) para avaliações. 


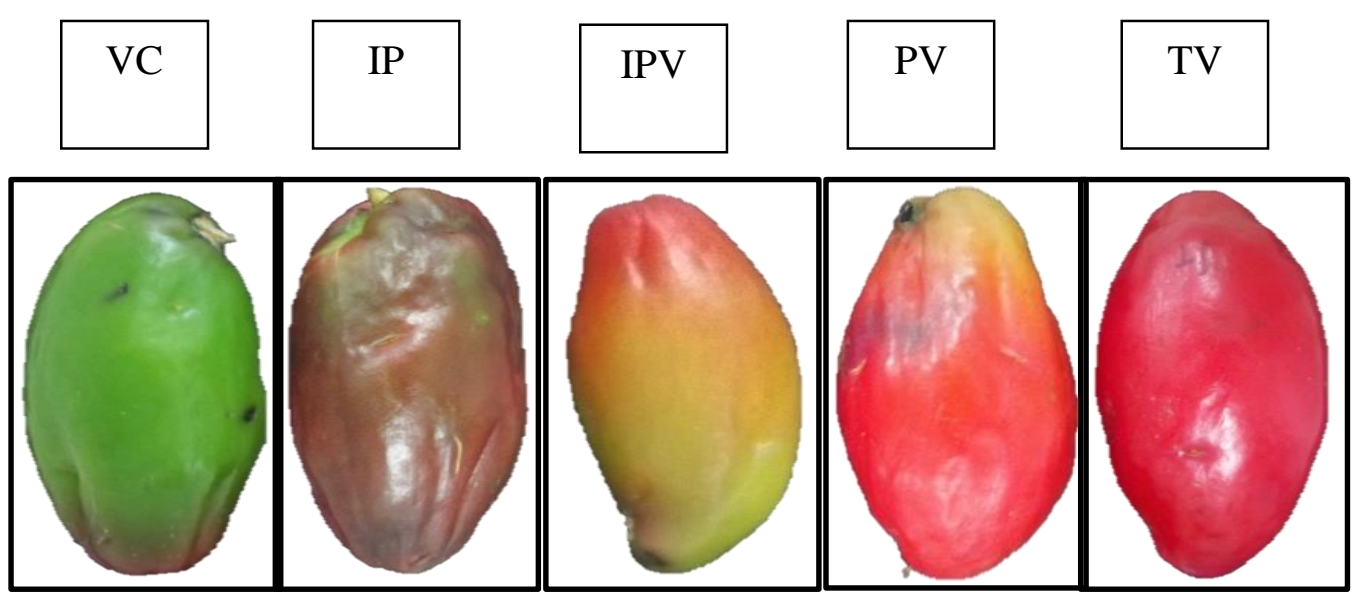

Figura 1 Evolução da maturação de frutos de Mandacaru (Cereus jamacaru), colhidos em diferentes bioclimas (Mesoregião Agreste e Microrregião Curimataú) do estado da Paraíba.

Tabela 1 Descrição dos estádios de maturação dos frutos de Mandacaru (Cereus jamacaru) com base na evolução da coloração da casca, colhidos em dois bioclimas do estado da Paraíba (Mesoregião Agreste e Microrregião Curimataú)

\begin{tabular}{cc}
\hline $\begin{array}{c}\text { Estádio de } \\
\text { Maturação }\end{array}$ & Descrição subjetiva da coloração \\
\hline VC & Verde Claro \\
IP & Inicio de Pigmentação \\
IPV & Inicio de Pigmentação Vermelho \\
PV & Pigmentado Vermelho \\
TV & Totalmente Vermelho \\
\hline
\end{tabular}

\subsection{Avaliações realizadas}

Massa Fresca dos frutos (g): Através de pesagem direta, utilizando a balança semi-analitica A $42207 \mathrm{c}$ - Bel Engeneering, sendo expresso em gramas $(\mathrm{g})$ de massa fresca;

Rendimento de Polpa (\%): Por diferença da massa dos frutos frescos, da massa da casca e da polpa com sementes.

Comprimento e Diâmetro do fruto: Determinados com o auxílio do paquímetro digital expressos em milímetros $(\mathrm{mm})$, obtendo as medidas na direção perpendicular e paralela ao eixo central dos frutos (Figura 2);

Firmeza (N): Determinada com penetrômetro Magness Taylor Pressure Tester, região de inserção de 2/16 polegadas de diâmetro;

Cor - Coloração de superfície: Determinada através de leitura direta no epicarpo com duas leituras em lados opostos na região equatorial dos frutos. As leituras foram realizadas com colorímetro Minolta CR- 300, com fonte de luz D 65 , com $8 \mathrm{~mm}$ de abertura. A coordenada $L^{*}$ expressa o grau de luminosidade da cor medida $\left(L^{*}=100=\right.$ branco; $L^{*}=0=$ preto). A coordenada $a^{*}$ expressa o grau de variação entre o vermelho e o verde ( $a^{*}$ mais negativo = mais verde; $a^{*}$ mais positivo $=$ mais vermelha). A coordenada $b^{*}$ expressa o grau de variação entre o azul e o amarelo $\left(b^{*}\right.$ mais negativo $=$ mais azul; $b^{*}$ mais positivo $=$ mais amarelo); $\mathrm{C}^{*}$ (Cromaticidade ou intensidade da cor) $e^{\circ} \mathrm{H}$ matizes cujos ângulos $0^{\circ}=$ vermelho, $90^{\circ}=$ amarelo, $180^{\circ}=$ verde, $270^{\circ}=$ azul $($ CALBO, 1989);

Sólidos solúveis (SS): Determinado com refratômetro de mesa Shimadzu, expressandose o resultado em \% conforme Association of Official Analytical Chemistry - AOAC (2005);

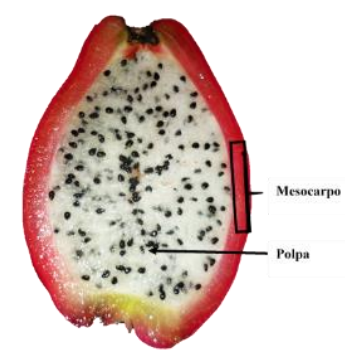

Figura 2 Esquema das partes do fruto que foram avaliadas: Mesocarpo (Casca) e endocarpo (polpa) com sementes de Cereus jamacaru (Mandacaru), colhidos de diferentes bioclimas do estado da Paraíba.

Acidez Titulavel (AT - g ácido cítrico $100 \mathrm{~g}^{-1}$ ): Foi determinada por titulometria com hidróxido de sódio $0,1 \mathrm{~N}$ utilizando-se 
fenolftaleína a $1 \%$ como indicador (AOAC, 2005);

Relação SS/AT: Pela divisão do teor de sólidos solúveis pela acidez titulável;

pH: Utilizando potenciômetro digital, conforme metodologia da AOAC (2005);

Ácido ascórbico (mg $\left.100 \mathrm{~g}^{-1}\right)$ : Determinado por titulometria, utilizando-se $1 \mathrm{~g}$ da amostra em $50 \mathrm{ml}$ de Ácido Oxálico 0,5\%, para titulação com solução de DFI (2,6-dicloro-fenolindofenol $0,002 \%$ ) até obtenção de coloração róseo claro permanente (STROHECKER e HENNING, 1967).

\subsection{Determinação da atividade antioxidante $e$ compostos fenólicos}

Obtenção do extrato fenólico: Obtido conforme metodologia descrita por Larrauri, Rupérez, e Saura-Calixto (1997). Utilizou-se $1,0 \mathrm{~g}$ de polpa congelada em ultra freezer a $-85^{\circ} \mathrm{C}$, adicionando $4 \mathrm{~mL}$ de metanol $50 \%$, deixando descansar por 1 hora para extração e centrifugado por 15 minutos em $9.000 \mathrm{rpm}$. Foi retirado o sobrenadante, colocando-o em tubo de ensaio graduado. Adicionou $4 \mathrm{~mL}$ de acetona $70 \%$ ao resíduo, deixando-se extrair por 1 hora, sendo centrifugado por 15 minutos em $9.000 \mathrm{rpm}$. O sobrenadante foi retirado e colocado junto com o primeiro sobrenadante, completando o volume para $10 \mathrm{~mL}$ com água destilada. Todo procedimento foi realizado no escuro. $\mathrm{O}$ extrato foi utilizado em até 4 dias, sendo conservado na geladeira;

Determinação dos Compostos Fenólicos (mg 100 $\mathrm{g}^{-1}$ ): Determinada de acordo com Larrauri, Rupérez, e Saura-Calixto (1997). Tomou-se uma alíquota de $200 \mu \mathrm{L}$ do extrato fenólico para a porção do mesocarpo e $500 \mu \mathrm{L}$ para a polpa, completando para $1000 \mu \mathrm{L}$ com água destilada. Essa diluição foi acrescida de $1 \mathrm{~mL}$ do reagente de Folin Ciocalteu, 2,0 mL de carbonato de sódio $20 \%$ e $2,0 \mathrm{~mL}$ de água destilada. Agitou-se o tubo de ensaio, deixando descansar por 30 minutos ao abrigo de luz. A leitura foi realizada em espectrofotômetro no comprimento de onda a $700 \mathrm{~nm}$;

Determinação da Atividade Antioxidante Total AAT ( $\mu$ M trolox / g): Determinada através da captura do radical livre ABTS (3etilbenzotiazolina-6-ácido sulfônico)
(DANTAS et al., 2015). A partir do extrato fenólico, foram preparadas três diluições (10, 20 e $30 \mu \mathrm{L} \cdot \mathrm{mL}^{-1}$ ), em triplicata, determinadas por testes prévios, tendo como base a curva padrão do ABTS. A partir do extrato obtido, foi preparado em tubos de ensaio as três diluições em triplicata e completado para 30 $\mu \mathrm{L}$ com água destilada. Logo após foi adicionado 3,0 $\mathrm{mL}$ do radical $\mathrm{ABTS}^{+} \mathrm{e}$ homogeneizado. A leitura foi feita a $734 \mathrm{~nm}$, após 6 minutos da mistura, e utilizou-se o álcool etílico como branco para calibrar o espectrofotômetro.

\subsection{Delineamento experimental e análise estatística}

$\mathrm{O}$ delineamento experimental para os frutos de Cereus jamacaru colhido em Campina Grande-PB e em Barra de Santa Rosa-PB foi inteiramente casualizado (DIC). Para as avaliações físicas foram utilizados 16 frutos de cada estádio de maturação, sendo cada fruto considerado uma repetição. Para as avaliações físico-químicas, polifenóis extraíveis totais e atividade antioxidante quatro repetições de 4 frutos foram utilizadas.

O delineamento foi inteiramente casualizado, sendo feito em esquema fatorial $(5 \mathrm{x}$ $2)$ e $(3 \times 2)$ respectivamente, sendo cinco e três estádios de maturação e 2 tipos de polpa (Figura 02), a polpa externa denominada de mesocarpo (casca) e a polpa interna, o endocarpo com sementes (polpa), em quatro repetições. O efeito da maturação na qualidade dos frutos foi avaliado pela análise de variância e as médias comparadas pelo teste de Tukey em até 5\% de probabilidade.

\section{Resultados e Discussão}

As características físicas para os frutos de mandacaru colhidos em Campina Grande-PB estão apresentadas na Tabela 2. Para as variáveis comprimento, diâmetro, massa e firmeza não houve diferença entre os estádios de maturação avaliados. Para o rendimento de polpa observouse que os estádios com início de pigmentação (IP) e o totalmente vermelho (TV), não diferiram entre si. Entretanto, o estádio TV foi o que apresentou o maior valor $(44,36 \%)$ diferindo do estádio VC $(29,37 \%)$. Essas s no rendimento de polpa podem ser atribuídas ao fato de que mesmo os frutos tendo tamanho próximos, a espessura do 
mesocarpo variava entre frutos e entre estádios de maturação.

Para os frutos colhidos em Barra de Santa Rosa (Tabela 2) o estádio início de pigmentação vermelha (IPV), foi o que apresentou o maior comprimento $(84,25 \mathrm{~mm})$. Para o diâmetro, o maior valor foi observado no estádio totalmente vermelho (TV), não diferindo do estádio IP. Bahia et al. (2010) caracterizando os mesmos frutos no estado de Pernambuco, para as duas características avaliadas (comprimento e diâmetro) encontrou valores próximos, sendo provavelmente devido as condições climáticas similares dos locais de colheita. A massa fresca do fruto, a firmeza e o rendimento da polpa não diferiu entre os estádios avaliados, com valores médios de $122,47 \mathrm{~g}, 11,91 \mathrm{~N}$ e $32,96 \%$ respectivamente. Silva e Alves (2009) estudando as características físicas dos frutos de mandacaru reportou valores superiores para massa de $241 \mathrm{~g}$, sendo esta variação, certamente devido aos genótipos avaliados estarem sob outras condições edafoclimáticas.

Tabela 2 Comprimento e Diâmetro (mm), Massa fresca (g), Firmeza (N) e rendimento da polpa (\%) de frutos de mandacaru, colhidos dos bioclimas da Mesoregião Agreste (Campina Grande-PB) e da Microrregião Curimataú (Barra de Santa Rosa-PB), em diferentes estádios de maturação

\begin{tabular}{|c|c|c|c|c|c|c|}
\hline Bioclima & Estádios de Maturação & $\begin{array}{l}\text { Comprimento } \\
-\end{array}$ & Diâmetro & $\begin{array}{l}\text { Massa } \\
--- \text { g --- }\end{array}$ & $\begin{array}{l}\text { Firmeza } \\
---N \text {--- }\end{array}$ & $\begin{array}{c}\text { Rendimento } \\
---\% \text {--- }\end{array}$ \\
\hline \multirow{5}{*}{$\begin{array}{l}\text { Mesoregião } \\
\text { Agreste }\end{array}$} & $\mathrm{VC}$ & $114,14 \mathrm{a}$ & $56,44 a$ & $181,33 a$ & $51,24 a$ & $29,73 b$ \\
\hline & IP & $109,23 a$ & $54,55 \mathrm{a}$ & $204,52 a$ & $48,79 \mathrm{a}$ & $37,76 \mathrm{ab}$ \\
\hline & IPV & $102,23 a$ & $61,17 \mathrm{a}$ & $205,21 \mathrm{a}$ & $44,94 \mathrm{a}$ & $37,38 \mathrm{ab}$ \\
\hline & VI & $104,88 \mathrm{a}$ & $62,91 \mathrm{a}$ & $172,95 a$ & $44,82 \mathrm{a}$ & $37,70 \mathrm{ab}$ \\
\hline & TV & $103,96 \mathrm{a}$ & $61,62 \mathrm{a}$ & $191,21 \mathrm{a}$ & $39,63 \mathrm{a}$ & $44,36 \mathrm{a}$ \\
\hline \multirow{2}{*}{\multicolumn{2}{|c|}{$\begin{array}{c}\text { Média Geral } \\
\text { C.V. }(\%)\end{array}$}} & 106,94 & 59,34 & 191,24 & 45,94 & 37,20 \\
\hline & & 16,92 & 16,60 & 47,58 & 23,99 & 21,31 \\
\hline \multirow{3}{*}{$\begin{array}{l}\text { Microrregião } \\
\text { Curimataú }\end{array}$} & IP & $70,85 b$ & $44,83 b$ & $79,42 \mathrm{a}$ & $12,98 \mathrm{a}$ & $29,22 \mathrm{a}$ \\
\hline & IPV & $84,25 \mathrm{a}$ & $55,08 \mathrm{ab}$ & $143,00 \mathrm{a}$ & $11,70 \mathrm{a}$ & $35,00 \mathrm{a}$ \\
\hline & TV & $83,18 \mathrm{ab}$ & $61,07 \mathrm{a}$ & $144,99 \mathrm{a}$ & $11,06 \mathrm{a}$ & $34,64 a$ \\
\hline \multirow{2}{*}{\multicolumn{2}{|c|}{$\begin{array}{c}\text { Média Geral } \\
\text { C.V. }(\%)\end{array}$}} & 79,43 & 53,66 & 122,47 & 11,91 & 32,96 \\
\hline & & 14,04 & 16,57 & 46,69 & 40,27 & 26,41 \\
\hline
\end{tabular}

*Médias seguidas de letras iguais, não diferem entre si pelo teste de Tukey ao nível de até 5\% de probabilidade. Estádios de maturação: VC=Verde claro; IP=Início de Pigmentação; IPV=Inicio de pigmentação Vermelho; PV=Pigmentado Vermelho; TV=Totalmente Vermelho; C.V (\%)=Coeficiente de variação.

Para o parâmetro de coloração L* (Tabela 3) observou-se que frutos de mandacaru oriundos da Mesoregião Agreste, não diferiram entre os primeiros estádios de maturação (VC e IP) sendo que esses dois com os maiores valores, caracterizando assim frutos mais brilhantes. $\mathrm{O}$ parâmetro $\mathrm{a}^{*}$ aumentou à medida que avançou a maturação do fruto, atingindo valor máximo de 23,98, ou seja, com o avanço da maturação os frutos foram perdendo a coloração verde $\mathrm{e}$ desenvolvendo a coloração avermelhada.

Comportamento contrário observou-se para o parâmetro $b^{*}$, que decresceu com o avanço da maturação, com maiores valores obtidos nos estádios iniciais, o verde claro (VC) e o com início de pigmentação (IP) com 23,65. Houve diferença entre os estádios para o ângulo Hue $\left({ }^{\circ} \mathrm{H}\right)$ com valor máximo de 84,32 no estádio $\mathrm{VC}$ e um mínimo de 30,44 no estádio TV.
Com relação aos frutos colhidos com maturação mais avançada da Microrregião Curimataú, o parâmetro $L^{*}$ que mede a luminosidade no fruto, não diferiu com o avanço da maturação, com média geral de 26,77, indicando que os frutos possuíam a mesma intensidade de brilho. Os valores de $a^{*}$ aumentaram do estádio IP (início de pigmentação) para o estádio totalmente vermelho (TV), diferindo entre os estádios, sendo o maior valor de 18,69 , evoluindo da cor verde para tom mais avermelhado.

O parâmetro de cor $b^{*}$, que mede o intermédio da coloração azul-amarelado, não variou entre os estádios de maturação, mas houve um pequeno declínio, que provavelmente decorreu do desenvolvimento da cor vermelho e desaparecimento de amarelo. A cromaticidade ou elevação na vividez da cor $\left(\mathrm{C}^{*}\right)$ apresentou aumento com a maturação, onde os estádios com 
início de pigmentação (IP) e pigmentado amarelo (PA) não diferiram, mas o estádio totalmente vermelho (TV) foi o que obteve o maior valor, atingindo 25,53 e diferindo dos outros. Já para o ângulo Hue, que trata da mudança de cor entre o verde e o vermelho (quanto mais próximo de 0 mais vermelho, e quanto mais longe, mais verde), podemos observar que com $\mathrm{o}$ avanço da maturação os frutos tenderam a ter uma cor mais avermelhada, tendo como valor de ângulo Hue 42,91 no ultimo estádio (totalmente vermelho), diferindo significativamente dos outros estádios.

Tabela 3 Mudanças médias na coloração da casca de frutos de mandacaru, expressa através dos parâmetros $L^{*}, a^{*}, b^{*}, C e^{o} H$ colhidos dos bioclimas da Mesoregião Agreste (Campina Grande-PB) e da Microrregião Curimataú (Barra de Santa Rosa-PB), em diferentes estádios de maturação

\begin{tabular}{|c|c|c|c|c|c|c|}
\hline Bioclima & Estádios de Maturação & $\mathbf{L}^{*}$ & $\mathbf{a}^{*}$ & $\mathbf{b}^{*}$ & $\mathbf{C}^{*}$ & $\mathbf{H}^{\mathbf{0}}$ \\
\hline \multirow{5}{*}{ Mesoregião Agreste } & $\mathrm{VC}$ & $29,83 a$ & $-3,70 c$ & $23,65 \mathrm{a}$ & $23,79 b c$ & $84,32 \mathrm{a}$ \\
\hline & IP & $31,41 \mathrm{a}$ & $3,56 b$ & $24,56 \mathrm{a}$ & $26,68 b$ & $69,22 b$ \\
\hline & IPV & $25,60 \mathrm{c}$ & $7,47 \mathrm{~b}$ & $16,96 \mathrm{c}$ & $21,84 \mathrm{c}$ & $52,09 \mathrm{c}$ \\
\hline & VI & $28,06 \mathrm{~b}$ & $20,28 \mathrm{a}$ & $20,03 b$ & $33,16 a$ & $37,59 \mathrm{~d}$ \\
\hline & TV & $26,92 \mathrm{bc}$ & $23,98 \mathrm{a}$ & $17,49 \mathrm{bc}$ & $34,76 \mathrm{a}$ & $30,44 d$ \\
\hline \multirow{2}{*}{\multicolumn{2}{|c|}{$\begin{array}{c}\text { Média Geral } \\
\text { C.V. }(\%)\end{array}$}} & 28,28 & 10,32 & 20,45 & 5,44 & 55,39 \\
\hline & & 4,19 & 22,43 & 9,56 & 10,34 & 11,11 \\
\hline \multirow{3}{*}{$\begin{array}{l}\text { Microrregião } \\
\text { Curimataú }\end{array}$} & IP & $26,77 \mathrm{a}$ & $7,22 \mathrm{c}$ & $17,96 a$ & $19,54 b$ & $68,19 \mathrm{a}$ \\
\hline & IPV & $26,75 \mathrm{a}$ & $13,12 b$ & $17,86 \mathrm{a}$ & $22,04 \mathrm{~b}$ & $54,38 \mathrm{~b}$ \\
\hline & TV & $26,79 \mathrm{a}$ & $18,69 \mathrm{a}$ & $17,14 \mathrm{a}$ & $25,53 \mathrm{a}$ & $42,91 \mathrm{c}$ \\
\hline \multirow{2}{*}{\multicolumn{2}{|c|}{$\begin{array}{l}\text { Média Geral } \\
\text { C.V. }(\%)\end{array}$}} & 26,77 & 13,01 & 17,65 & 22,37 & 55,16 \\
\hline & & 5,42 & 25,80 & 7,42 & 10,95 & 12,52 \\
\hline
\end{tabular}

*Médias seguidas de letras iguais, não diferem entre si pelo teste de Tukey ao nível de até 5\% de probabilidade. Estádios de maturação: VC=Verde claro; IP=Início de Pigmentação; IPV=Inicio de pigmentação Vermelho; PV=Pigmentado Vermelho; TV=Totalmente Vermelho; C.V $(\%)=$ Coeficiente de variação.

O conteúdo de sólidos solúveis (SS) dos frutos do mandacaru oriundos da Mesoregião Agreste, aumentou com o avanço da maturação (Tabela 4). Observou-se diferença entre os estádios avaliados, com valor máximo de $14,30 \%$ desse conteúdo para o estádio totalmente vermelho (TV). Para a acidez titulável (AT) houve diferença significativa entre os estádios e

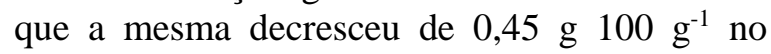
estádio $\mathrm{VC}$ e atingiu valor mínimo no estádio

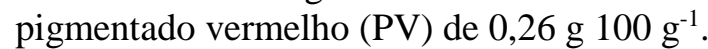

$\mathrm{O}$ pH diferiu entre os estádios de maturação. Baseado na classificação de Baruffaldi e Oliveira (1998) a polpa de frutos de mandacaru são considerados como produtos ligeiramente ácidos ( $\mathrm{pH}$ entre 3,7 e 4,5). O conteúdo de ácido ascórbico diferiu entre os estádios de maturação partindo de um valor mínimo de 2,16 para o estádio VC e chegando a

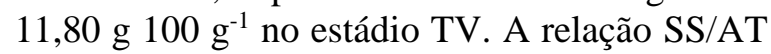
aumentou com a maturação sendo que entre os dois estádios iniciais não diferiram entre si mas diferiu dos três estádios próximos.

Observa-se para os frutos provindos da Microrregião Curimataú (Tabela 4) que a medida que ocorre a evolução da maturação, o teor de sólidos solúveis (SS) aumenta, sendo o estádio totalmente vermelho (TV) o que apresentou o maior teor $(16,63 \%)$ não diferindo, entretanto, do estádio intermediário IPV, mas sendo superior ao IP. Todos os valores de SS foram superiores aos reportados por Silva e Alves (2009) com teor médio de $11 \%$ de SS. Bahia (2009) caracterizando frutos de outra região, observou teor próximo ao deste trabalho, cerca de $14 \%$. A acidez titulável foi baixa, que diferiu entre os estádios, sendo a maior, com um valor de $0,37 \mathrm{~g}$ $100 \mathrm{~g}^{-1}$ e diminuindo para $0,21 \mathrm{~g}^{100 \mathrm{~g}^{-1} \mathrm{no}}$ estádio TV.

Silva e Alves (2009) caracterizando os atributos físico-químicos da polpa de mandacaru encontraram valores inferiores aos deste trabalho que foi de $0,05 \mathrm{~g} 100 \mathrm{~g}^{-1}$ e $0,29 \mathrm{~g} 100 \mathrm{~g}^{-1}$ respectivamente, fato que pode ser explicado devido os frutos terem sido colhidos em estádio de maturação mais avançado. Para a relação entre sólidos solúveis e acidez titulável (SS/AT), devido o conteúdo de SS ter sido alto e a AT relativamente baixa, esta aumentou com a maturação do fruto, diferindo entre os estádios. O $\mathrm{pH}$ apresentou comportamento similar à relação 
SS/AT, diferindo entre os estádios e aumentando durante a maturação.

Em frutos de mandacaru classificados como maduros Silva e Alves (2009), reportaram $\mathrm{pH}$ de 4,4, inferior ao observado neste trabalho para o estádio IP $(4,87)$, sendo que aumentou com a maturação dos frutos, provavelmente devido a diferença das condições edafoclimáticas e também a época de colheita dos frutos. Também deve-se levar em conta a amplitude de amostragem de frutos deste trabalho que permitiu resultados mais abrangentes e mais representativos. O conteúdo de ácido ascórbico de mandacaru é baixo e não diferiu entre os estádios de maturação avaliados, estando em média entre de $4,01 \mathrm{~g} .100 \mathrm{~g}^{-1}$. Entretanto, verificou-se um aumento nos estádios IP e IPV para o estádio totalmente vermelho TV, variando de 3,71 a 4,61 g. $100 \mathrm{~g}^{-1}$ de ácido ascórbico, indicando assim uma tendência de aumento no conteúdo de ácido ascórbico com o avanço da maturação. No geral, as características de qualidade de frutos de mandacaru se estabilizaram a partir do estádio início da pigmentação vermelha (IPV), indicando ser este o mínimo estádio de colheita para obtenção da qualidade comestível.

Tabela 4 Sólidos Solúveis (SS), Acidez Titulável (AT), Potencial Hidrogeniônico, Ácido Ascórbico e Relação Sólidos Solúveis/Acidez (SS/AT) de frutos de mandacaru colhidos dos bioclimas da Mesoregião Agreste (Campina Grande-PB) e da Microrregião Curimataú (Barra de Santa Rosa-PB), em diferentes estádios de maturação

\begin{tabular}{|c|c|c|c|c|c|c|}
\hline Bioclima & Estádios de Maturação & $\begin{array}{c}\mathbf{S S} \\
----\end{array}$ & 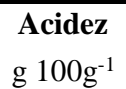 & pH & 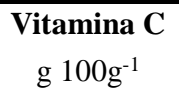 & SS/AT \\
\hline \multirow{5}{*}{ Mesoregião Agreste } & $\mathrm{VC}$ & $9,93 \mathrm{~d}$ & $0,45^{\mathrm{a}}$ & $4,09 \mathrm{bc}$ & $2,16 \mathrm{~d}$ & $22,22 b$ \\
\hline & IP & $10,83 \mathrm{~cd}$ & $0,42 b$ & $4,19 \mathrm{ab}$ & $3,76 \mathrm{c}$ & $25,74 b$ \\
\hline & IPV & $11,67 b c$ & $0,28 \mathrm{~d}$ & $4,26 \mathrm{a}$ & $2,10 \mathrm{~d}$ & $41,97 \mathrm{a}$ \\
\hline & PV & $11,97 \mathrm{~b}$ & $0,26 \mathrm{~d}$ & $4,15 \mathrm{ab}$ & $8,44 \mathrm{~b}$ & $45,33 \mathrm{a}$ \\
\hline & TV & $14,30 \mathrm{a}$ & $0,33 \mathrm{c}$ & $4,00 \mathrm{c}$ & $11,80 \mathrm{a}$ & $43,81 \mathrm{a}$ \\
\hline \multirow{2}{*}{\multicolumn{2}{|c|}{$\begin{array}{c}\text { Média Geral } \\
\text { C.V. }(\%)\end{array}$}} & 11,74 & 0,35 & 4,14 & 5,65 & 35,81 \\
\hline & & 3,33 & 2,69 & 1,01 & 5,59 & 6,76 \\
\hline \multirow{3}{*}{$\begin{array}{c}\text { Microrregião } \\
\text { Curimataú }\end{array}$} & IP & $12,37 b$ & $0,37 \mathrm{a}$ & $4,87 \mathrm{c}$ & $3,71 \mathrm{a}$ & $33,75 \mathrm{c}$ \\
\hline & IPV & $15,80 \mathrm{a}$ & $0,28 \mathrm{~b}$ & $5,06 \mathrm{~b}$ & $3,72 \mathrm{a}$ & $56,77 \mathrm{~b}$ \\
\hline & TV & $16,63 \mathrm{a}$ & $0,21 \mathrm{c}$ & $5,11 \mathrm{a}$ & $4,61 \mathrm{a}$ & $78,96 \mathrm{a}$ \\
\hline \multirow{2}{*}{\multicolumn{2}{|c|}{$\begin{array}{c}\text { Média Geral } \\
\text { C.V. }(\%)\end{array}$}} & 14,93 & 0,29 & 5,01 & 4,01 & 56,49 \\
\hline & & 3,88 & 3,31 & 0,33 & 10,99 & 4,94 \\
\hline
\end{tabular}

*Médias seguidas de letras iguais, não diferem entre si pelo teste de Tukey ao nível de até 5\% de probabilidade. VC=Verde claro; IP=Início de Pigmentação; IPV=Inicio de pigmentação Vermelho; PV=Pigmentado Vermelho; TV=Totalmente Vermelho; C.V (\%)=Coeficiente de variação.

$\mathrm{Na}$ Tabela 5 estão apresentados os conteúdos de polifenóis extraíveis totais (PET) e a atividade antioxidante total (AAT) de frutos provindo da Mesoregião Agreste e Microrregião Curimataú. Observou-se que a comparação entre as porções (casca e polpa) para os dois atributos diferiu, sendo na casca encontrados os maiores valores. Na casca (mesocarpo), para o conteúdo de PET, diferiu entre os estádios e aumentou durante a maturação, com os maiores valores obtidos nos estádios IPV, VI e TV, com média

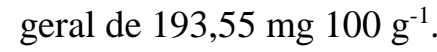

Para a porção polpa (endocarpo com sementes) observou-se diferença entre estádios de maturação, com maior valor para o estádio IP, com $85,55 \mathrm{mg} \cdot 100 \mathrm{~g}^{-1}$. A atividade antioxidante total apresentou maiores valores na porção casca, mas na porção casca os estádios não diferiram no decorrer da maturação, com média geral de 11,29 $\mu \mathrm{M}$ trolox / g. Na porção da polpa foi possível observar que houve diferença entre o estádio IP em comparação com os demais (VC; IPV; VI e TV) sendo o valor da AAT neste de 8,73 $\mu \mathrm{M}$ trolox / g.

Para os frutos colhidos na Microrregião Curimataú o conteúdo de PET também diferiu entre as porções casca e polpa, sendo aproximadamente $30 \%$ maior na casca. Na porção casca, o estádio que mais se destacou foi o IP com um valor de $177,16 \mathrm{mg} \cdot 100 \mathrm{~g}^{-1}$. Além disso, observou-se a diminuição do teor de PET à medida que avançava a maturação, atingindo o teor mínimo de $147,99 \mathrm{mg} 100 \mathrm{~g}^{-1}$.

$\mathrm{Na}$ porção polpa ocorreu o inverso, os teores de PET aumentaram com o avanço da maturação, com $29,78 \mathrm{mg} \cdot 100 \mathrm{~g}^{-1}$ no estádio IP até $61,26 \mathrm{mg} \cdot 100 \mathrm{~g}^{-1}$ no estádio TV. A atividade 
antioxidante total (AAT) também diferiu entre as porções. Na porção casca os teores aumentaram com a maturação, atingido um valor máximo de $10,14 \mu \mathrm{M}$ trolox / g. Na porção da polpa ocorreu o inverso, os valores diminuíram com a maturação dos frutos, iniciando valor máximo de $8,37 \mu \mathrm{M}$ trolox / g no estádio de maturação verde (VC), atingindo valor mínimo de 4,93 $\mu \mathrm{M}$ trolox $/ \mathrm{g}$ (cerca de 50\% inferior) no fruto com maturação completa (TV).
Assim como observado para as características físico-químicas, teores de PET e a AAT tenderam a se estabilizar a partir do estádio início da pigmentação vermelha (IPV), confirmando ser este o mínimo estádio de maturação de colheita para frutos de mandacaru visando a obtenção da máxima qualidade comestível.

Tabela 5 Conteúdos médios de Polifenóis Extraíveis Totais - PET (mg 100 g-1) e Atividade Antioxidante Total - AAT ( $\mu$ M trolox / g) da casca e polpa dos frutos de mandacaru, colhidos dos bioclimas da Mesoregião Agreste (Campina Grande-PB) e da Microrregião Curimataú (Barra de Santa Rosa-PB), em diferentes estádios de maturação

\begin{tabular}{|c|c|c|c|c|c|}
\hline \multirow{2}{*}{ Bioclima } & \multirow{2}{*}{ Estádios de Maturação } & \multicolumn{2}{|c|}{ PET $\left(m g 100 g^{-1}\right)$} & \multicolumn{2}{|c|}{$\mathrm{AAT}(\mu \mathrm{M}$ trolox $/ \mathrm{g})$} \\
\hline & & CASCA & POLPA & CASCA & POLPA \\
\hline \multirow{5}{*}{ Mesorregião Agreste } & $\mathrm{VC}$ & $103,26 \mathrm{Ac}$ & $23,85 \mathrm{Bc}$ & $11,17 \mathrm{Aa}$ & $5,36 \mathrm{Bb}$ \\
\hline & IP & $196,79 \mathrm{Ab}$ & $85,55 \mathrm{Ba}$ & $11,28 \mathrm{Aa}$ & $8,73 \mathrm{Ba}$ \\
\hline & IPV & $227,13 \mathrm{Aa}$ & $54,31 \mathrm{Bb}$ & $11,39 \mathrm{Aa}$ & $5,44 \mathrm{Bb}$ \\
\hline & PV & $217,37 \mathrm{Aab}$ & $63,20 \mathrm{Bab}$ & $11,30 \mathrm{Aa}$ & $5,32 \mathrm{Bb}$ \\
\hline & TV & $223,22 \mathrm{Aa}$ & $59,04 \mathrm{Bb}$ & $11,29 \mathrm{Aa}$ & $5,83 \mathrm{Bb}$ \\
\hline \multirow{2}{*}{\multicolumn{2}{|c|}{$\begin{array}{l}\text { Média Geral } \\
\text { C.V. }(\%)\end{array}$}} & 193,55 & 57,19 & 11,29 & 6,14 \\
\hline & & 13,83 & 13,83 & 10,74 & 10,74 \\
\hline \multirow{3}{*}{$\begin{array}{c}\text { Microrregião } \\
\text { Curimataú }\end{array}$} & IP & $177,16 \mathrm{Aa}$ & $29,78 \mathrm{Ab}$ & $6,88 \mathrm{Ab}$ & $8,37 \mathrm{Aa}$ \\
\hline & IPV & $153,56 \mathrm{Ab}$ & $49,06 \mathrm{Aa}$ & $8,31 \mathrm{Aab}$ & $5,93 \mathrm{Bb}$ \\
\hline & TV & $147,99 \mathrm{Ab}$ & $61,26 \mathrm{Aa}$ & $10,14 \mathrm{Aa}$ & $4,93 \mathrm{Bb}$ \\
\hline \multirow{2}{*}{\multicolumn{2}{|c|}{$\begin{array}{c}\text { Média Geral } \\
\text { C.V. }(\%)\end{array}$}} & 159,57 & 46,70 & 8,44 & 6,41 \\
\hline & & 12,24 & 12,24 & 27,04 & 27,04 \\
\hline
\end{tabular}

*Médias seguidas de letras iguais, minúsculas na coluna e maiúsculas na linha, para casca e polpa não diferem entre si pelo teste de Tukey ao nível de até $5 \%$ de probabilidade. VC=Verde claro; IP=Início de Pigmentação; IPV=Inicio de pigmentação Vermelho; PV=Pigmentado Vermelho; TV=Totalmente Vermelho.

\section{Com base na estabilidade das} características de qualidade, nos teores de ácido ascórbico, polifenóis extraíveis totais e atividade antioxidante, o estádio de maturação início da pigmentação vermelha (IPV) é o mínimo estádio em que frutos de mandacaru pode ser colhido para a obtenção da máxima qualidade de consumo;

Os frutos do mandacaru completamente maduros apresentam elevado rendimento de polpa. A coloração do epicarpo evoluiu na maturação de verde pigmentado para a coloração avermelhada. Os sólidos solúveis, a relação SS/AT e pH aumentam com o avanço da maturação, enquanto a acidez titulável diminui;

Os frutos de mandacaru apresentam um alto conteúdo de polifenóis extraíveis totais em estádios mais maduros e que resulta em relevante atividade antioxidante total. Isto, juntamente às características físico-químicas nestes estádios, justificam, portanto, o seu consumo como fruto fresco, além de servir como estimulo ao seu melhor aproveitamento.

\section{Referências}

ANDERSON, E. F. The cactus family. Portland: Timber Press, Portland, 2001.776p.

ANDRADE, C. T. S.; MARQUES, J. G. W.; ZAPPI, D. C. Utilização de cactáceas por sertanejos baianos. Tipos conexivos para definir categorias utilitárias. Sitientibus, Série Ciências Biológicas, v. 6, p. 3-12, 2006.

AOAC. Official methods of analysis of the Association of Official Analytical Chemistry. 19. ed. Washington: AOAC, 2005.

BAHIA, E. V. A. et al. Estudo das características físico-químicas do fruto do mandacaru (Cereus jamacaru P.DC.) cultivado no Sertão Pernambucano In: Congresso de Pesquisa e Inovação da Rede Norte Nordeste de Educação 
Tecnológica (CONNEPI), 5., 2010. Anais...Maceió: IFAL, 2010.

BARUFFALDI, R.; OLIVEIRA, M. N. Fatores que condicionam a estabilidade de alimentos. In: BARUFFALDI, R.; OLIVEIRA, M. N. Fundamentos de tecnologia de alimentos. São Paulo: Atheneu, 1998. v. 3. p. 13-25.

CALBO, C. Outros sistemas de medida: Hunter, Munsell, etc. In: Universidad de Chile, El Color en alimentos. Medidas Instrumentales. Universidad de Chile, Faculdad de Ciencias Agrarias y Forestales, p.36-47, 1989 (Publicaciones Miscelanes Agrícolas, 31).

DANTAS, R. L. et al. Changes during maturation in the bioactive compounds and antioxidant activity of Opuntia stricta (HAW.) Fruits. Acta Horticulturae, v. 1067, 159-165, 2015.

DAVET, A. et al. Atividade antibacteriana de Cereus jamacaru DC., Cactaceae. Revista Brasileira de Farmacognosia, v. 19, n. 2B, p. 561-564, 2009.

GALINDO, A. et al. Sensory and physicochemical quality attributes of jujube fruits as affected by crop load. LWT-Food Science and Technology, v. 63, n. 2, pp.899-905, 2015.

GARCÍA-CRUZ, L. et al. Postharvest quality, soluble phenols, betalains content, and antioxidant activity of Stenocereus pruinosus and Stenocereus stellatus fruit. Postharvest Biology and Technology, v. 31, n. 11. P. 69-76, 2016.

HERNÁNDEZ-GONZÁLEZ,

O.; VILLARREAL, O. B. Crassulacean acid metabolism photosynthesis in columnar cactus seedlings during ontogeny: the effect of light on nocturnal acidity accumulation and chlorophyll fluorescence. American Journal of Botany, v. 94, n. 8, p. 1344-1351, 2007.

LARRAURI, J.A.; RUPÉREZ, P.; SAURACALIXTO, F. Effect of drying temperature on the stability of polyphenols and antioxidant activity of red grape pomace peels. J. gric. Food Chemistry. v. 45, p. 1390-1393. 1997.

LORENZI, H. E.; MATOS, F. J. A. Plantas medicinais no Brasil: nativas e exóticas. Nova Odessa, SP: Instituto Plantarum, 2002. 512p.
LUCENA, C. M. et al. Conhecimento botânico tradicional sobre cactáceas no semiárido do Brasil. Gaia scientia. Edição especial cactaceae, v. 9, n. 2 77-90, 2015.

MESSIAS, J. B. et al. Avaliação dos parâmetros hematológicos e bioquímicos de ratas no segundo terço da gestação submetidas à ação de extrato metanólico de Cereus jamacaru D. C.; Cactaceae. Revista Brasileira de Farmacognosia, v. 20, p. 478-483, 2010.

NEPAL, V. P. et al. Determinants of fruit and vegetables consumption among persons with doctor-diagnosed chronic diseases. Journal of Primary Care \& Community Health, v. 3, p. 132-141, 2012.

NUNES, J. T. et al. Caracterização química e colorimétrica da polpa do mandacaru. Associação Brasileira de Educação Agrícola Superior - ABEAS, v. 28, n. 2, p. 102-106, 2013.

PAULINO, R. C. et al. Riqueza e importância das plantas medicinais do Rio Grande do Norte. Revista de Biologia e Ciências da Terra, v. 11, p. 157-168, 2011.

ROCHA, E. A.; AGRA, M. F. Flora of the Pico do Jabre, Paraíba, Brazil: Cactaceae Juss. Acta Botanica Brasilica, v. 16, n. 1, p.15-21, 2002.

SALES, M. D. S. L. et al. Cereus jamacaru de candolle (Cactaceae), o mandacaru do Nordeste Brasileiro. Publicatio UEPG: Ciências Biológicas e da Saúde, v. 20, n. 2, p. 135-42, 2015.

SHEWFELT, R. L. What is quality? Postharvest Biology and Technology, v. 15, p. 197 e 200, 1999.

SILVA, L. R.; ALVES, R. E. Avaliação da composição físico-química de frutos de mandacaru (Cereus jamacaru P.). Acta Agronómica, v. 58, n. 4, p. 245-250, 2009.

STROHECKER, R.; HENINING, H. M. Análises de vitaminas: métodos comprobrados, v. 42 p. 1967.

WANG, S. et al. How natural dietary antioxidants in fruit, vegetables and legumes promote vascular health. Food Research International, v. 44, 14-22, 2011. 